\title{
Keeping Up With The Internet
}

\author{
by \\ Jacqueline Dealy
}

\begin{abstract}
The Internet has enormous power to change the way information and education professionals do their work. It is a suitable environment for reference and already has strong links with education, especially in the areas of distance education and educational technology. This article presents the Internet novice with instructions on how to get connected. It also presents a sample of library and education related resources and provides sources for an information professional to use to keep up to date.
\end{abstract}

Much has been written extolling the seemingly limitless resources of the Internet. To make effective use of its resources and not get caught up in irrelevant information requires making an effort to map out those parts of the Internet that can be useful to you.

An earlier article in this journal covered background and services on the Internet ${ }^{1}$ and a second, its potential as a resource for teaching and research. ${ }^{2}$ Yet another, a bibliography, bears witness to the flood of material being written on this subject. ${ }^{3}$ The purpose of this article is threefold: one, to assemble a sample of education and library related resources; two, to present some useful tips and sources for keeping up to date; and three, to help clarify the often cryptic instructions that are the key to the riches of networking. An Internet novice should find enough information in what follows to get started and keep going.

The information will be organized around Internet services: Listserv, Electronic Journals, Telnet, Archie, Gopher and Veronica. Like the Internet itself where there seems to be no beginning and no end, there is no real beginning or end to this article. The reader will want to refer back and forth from one section to the other or skip straight to the middle if he or she wishes.

\section{Disclaimer}

It is impossible to write about the Internet without inserting a disclaimer or two. First of all, developments in networking are occurring daily; some (a small percentage) of what is written here will have changed by the time of publication. Secondly, this article will not discuss the various differences between local operating systems and telecommunications software or between networking protocols. These are best clarified by local systems supportpersonnel. Third, at the micro level there are dissimilarities between Macintosh and PC environments to be taken into account. Once you get beyond the local system, however, whether you are pointing and clicking or typing your commands, the basics of the Internet remain the same.

\section{Special Interest Discussion Groups: Listservs}

One of the easiest ways to get to know the Internet is to join a special interest discussion group. On the Internet these groups are referred to as 'lists'. Individual lists revolve around a particular topic and may have anywhere from several hundred to several thousand persons subscribed. Each list has a co-ordinator and/or a home institution or sponsoring organization. With very few exceptions, a list, and many of the housekeeping functions involved in maintaining subscriptions, is managed by software called LISTSERV. That is to say, when you join a list or cancel your subscription to a list, your requests are executed by a computer. All interactions with a Listserv are sent via electronic mail using the conventions for sending messages that are peculiar to your computer site. It is important to understand that there is no human intermediary at this point of the operation and because of this, your instructions must be precise and sent in the accepted command language recognized by the Listserv software. Two basic commands to get started with are SUBSCRIBE and UNSUBSCRIBE. These commands are often abbreviated to SUB and UNSUB. A variation on UNSUB, used on some lists is SIGNOFF. Upon request you can ask the LISTSERV to send instructions for more complex interactions.

When you subscribe to a list you will be sent a welcome letter by the list owner telling you about the list. You will also receive a message from the Listserv with instructions on other Listserv Commandssuch as how to put your mail on hold and how toleave the list. When you join a list you will be told whether or not it is moderated, which means that when a message is sent to the list, 
it must meet certain criteria before it is 'posted' for the list members to read.

It is a good idea to monitor a list for a short period of time before you begin 'posting' messages so as to get a feel for the tone and nature of the 'conversation'. Network etiquette has evolved over time and is a must. If the list you subscribe to does not send you information on 'netiquette' a few rules to follow can be found in Ed Krol's, The Whole Internet User's Guide and Catalog. 4

\section{Subscribing to a List}

The way to join a discussion group is to send an electronic mail niessage addressed to the Listserv that manages the list you want to join. In the few cases where the list is not managed by a Listserv the instructions remain essentially the same, with the difference being the mail message is sent to a person rather than to a Listserv.

An example of a Listserv address is: Listserv@ uhupvm1.uh.edu. ${ }^{5}$ To subscribe to a list send a message to a designated list address using the established mail protocols of your system.

After you have entered the address, leave the subject line blank and type the following in the body of the text:

\section{SUBSCRIBE <Listname> Yourfirstname Yourlastname}

Your Firstname and your Lastname should be the name with which you registered on your local system.

To cancel your subscription to a list, send the following electronic mail message to the Listserv:

\section{UNSUBSCRIBE <Listname >}

Do not put your first and last name in your unsubscribe message. If you are subscribed, the Listserv knows who you are and will be confused by the presence of more information on the UNSUB line.

\section{Education and Library Related Lists}

There are literally hundreds of lists to subscribe to with no limit to the subjects covered. For obvious reasons, the fields of education and libraries are a natural for the Internet. Adult education, education technology and distance education, in particular, lend themselves well to networking. K12 education is also gaining a presence through Fidonet and other Bulletin Board Systems, while those of us working in libraries and information centers are filling the networks with communications on how to handle the network.

Many lists are regional in nature, being confined to topics that are of local interest to a state or a province. Other lists may be moderated or archived by a state institution and may appear to have a geographical orientation but are often international in coverage. The best way to get to know a list is to subscribe to one.

A few of the many, many discussion groups that are avail- able for librarians and educators are mentioned below. Due to lack of space and the unpredictable nature of lists, the description is necessarily brief. To find out about other lists, refer to the sources in the section of this article on Keeping In Touch With The Internet. To subscribe to one or more lists follow the basic instructions outlined below. Most follow the same procedure. If the procedure for a list varies it will be mentioned. The lists are in alphabetical order. Remember, this is just a sample of what is available.

\section{ADLTED-L - Canadian Adult Education Network}

The ADLTED-L list provides an opportunity for adult educators from Canada and abroad to communicate with one another. Discussion on this list tends to be thoughtful. To join ADLTED-L, send an electronic mail message to: Listserv@ uregina.uregina.ca. After you have entered the address, leave the subject line blank and type the following in the body of the text:

\section{SUBSCRIBE Adlted-1 Yourfirstname Yourlastname}

\section{AEDNET - Adult Education Network}

AEDNET is a list for discussion, information exchange, announcements and queries on topics of interest to adult educators. A refereed electronic journal, New Horizons in Adult Education is distributed through Aednet (see journal section below). To subscribe to AEDNET, send an electronic mail message to: Listserv@alpha.acast.nova.edu. After you have entered the address, leave the subject line blank and type the following in the body of the text:

\section{SUBSCRIBE Aednet Yourfirstname Yourlastname}

\section{AERA-A American Educational Research Association}

AERA-A is a joint effort of the College of Education at Arizona State University and the American Educational Research Association. There are eleven AERA forums, which grew out of the Education Research List (ERL-L). Each AERA forum is a separate list corresponding to a division of AERA and is identified by a letter of the alphabet as follows:

AERA-ADivision A - Administration

AERA-BDivision B - Curriculum Studies

AERA-CDivision $C$ - Learning and Instruction

AERA-DDivision D - Measurement and Research Methodology

AERA-EDivision E - Counselling and Human

Development

AERA-FDivision F - History and Historiography

AERA-GDivision G - Social Context of Education

AERA-HDivision $\mathrm{H}$ - School Evaluation/Program 
Development

AERA-IDivision I - Education in the Professions

AERA-JDivision J - Postsecondary Education

AERA-KDivision $\mathrm{K}$ - Teaching and Teacher Education

To subscribe to one of the lists, send an electronic mail message to: Listserv@asuacad.bitnet. After youhave entered the address, leave the subject line blank and type the following in the body of the text:

SUBSCRIBE Aera-k Yourfirstname Yourlastname

To join more than one AERA list, place individual messages on separate lines.

\section{ALTLEARN}

As the name of this list suggests, it is devoted to discussion ofalternativeapproaches to learning. To subscribe to ALTLEARN send an electronic mail message to: Listserv@sjuvm.bitnet. After you have entered the address, leave the subject line blank and type the following in the body of the text:

\section{SUBSCRIBE Altlearn Yourfirstname Yourlastname}

\section{DEOS-L Distance Education Online Symposium}

DEOS-L is an international forum on distance education. The purpose of this list is to facilitate discussion on the issues presented in DEOSNEWS (see journal section below) plus other issues of interest to distance educators. To subscribe to DEOS-L, send an electronic mail message to: Listserv@psuvm.edu. After you have entered the address, leave the subject line blank and type the following in the body of the text:

\section{SUBSCRIBE Deos-1 Yourfirstname Yourlastname}

\section{EDPOLYAN - Education Policy Analysis Forum}

This list presents a forum for the various aspects of education policy. EDPOLYAN also serves as a bulletin board for posting jobs, meetings and education policy publications. To subscribe to EDPOLYAN, send an electronic mail message to: Listserv@ asuacad.bitnet. After you have entered the address, leave the subject line blank and type the following in the body of the text:

SUBSCRIBE Edpolyan Yourfirstname Yourlastname

\section{EDTECH}

EDTECH is a list for students and faculty in the field of educational technology. It discusses problems and solutions in educational technology, education resources, news events and current research. To subscribe to EDTECH send an electronic mail message to: Listserv@msu.bitnet. After you have entered the address, leave the subject line blank and type the following in the body of the text:

SUBSCRIBE Edtech Yourfirstname Yourlastname

\section{K12ADMIN}

K12ADMIN is a world-wide discussion group centred on K12 school administration. Conversation focuses on curriculum, operations, technology and activities. To join K12ADMIN, send an electronic mail message to: Listserv@suvm.bitnet. After you have entered the address, leave the subject line blank and type the following in the body of the text:

\section{SUBSCRIBE K12admin Yourfirstname Yourlastname}

\section{KID-MEDIA}

KID-MEDIA list encourages communication between people interested or involved in the creation, production, distribution and consumption of media targeted at children. It is aimed primarily at children under the age of 12 . Topics include: children's public and commercial television, the role of computers and computer animation, and social issues such as separating illusion from reality in kids media. Note: KID-MEDIA is not handled by a Listserv. To join KID MEDIA send an electronic mail message to: kid.media-request@airwaves.chi.il.us. Type the word 'subscribe' in the SUBJECT line. Do not include a message. Do not add your name.

\section{LIBREF-L}

LIBREF-L is a list that focuses on library reference issues. It is a well established list that appeared relatively early in the history of lists. The discussion is mixed between academic and other types of libraries. The very nature of the Internet, however, tilts the balance toward the academic side. Many good natured people belong to this list, who are willing not only to discuss reference issues but to answer difficult reference questions. To subscribe to LIBREF-L, send an electronic mail message to: Listserv@kentvm.bitnet. After you have entered the address, leave the subject line blank and type the following in the body of the text:

SUBSCRIBE Libref-1 Yourfirstname Yourlastname

$$
\text { LM_NET (Library Media) }
$$

The LM_NET list is for school library media specialists and people involved in the school library media field. LM_NET sponsors a 'Skills Index', which is a list of names and electronic 
mail addresses of persons who have volunteered to answer questions related to network resources. LM_NET monitors other Listserv discussion groups with related interests such as MEDIA-L, HYPERCRD and EDTech. To subscribe to LM_NET, send an electronic mail message to: Listserv@suvm.syr.edu. After you have entered the address, leave the subject line blank and type the following in the body of the text:

\section{SUBSCRIBE Lm_net Yourfirstname Yourlastname}

OTELA-L Ontario Teacher

Education Library Association

The purpose of OTELA-L is to share news and ideas and to discuss issues affecting Canadian education libraries. The list is sponsored through a jointeffort of OTELA and Brock University Faculty of Education. To join OTELA-L send an electronic mail message to: Listserv@dewey.ed.brocku.ca. After you have entered the address, leave the subject line blank and type the following in the body of the text:

\section{SUBSCRIBE Otela-l Yourfirstname Yourlastname}

\section{PACS-L Public Access Computer Systems}

PACS- $L$ is a list that focuses on the use of computer technology in libraries. Topics include CD-ROM, new software and hardware, information retrieval, conferences and other news announcements. To join PACS-L send an electronic mail message to: Listserv@uhupvm1.bitnet. After you have entered the address, leave the subject line blank and type the following in the body of the text:

\section{SUBSCRIBE Pacs-1 Yourfirstname Yourlastname}

\section{Searching a List}

The contents of past messages on a list can be searched by sending search commands to a Listserv. A Listserv can handle simple searches and fairly complex searches involving boolean logic and limit features. Even a simple Listserv search, however, involves somewhat cryptic syntax. Some gopher sites allow you to search lists through the gopher menu or through Veronica software both of which are explained below. However, if you want to look for information that has appeared in an earlier discussion in a specific list without going through a gopher, a Listserv database search is possible. It is also more explicit and requires less time than sifting through repetitive items retrieved by a Veronic search of different gophers. Frankly, each search method has its advantages and disadvantages. Their individual usefulness depends on the desired result. As you become familiar with both processes you will be able to decide which is best for you.

To search a list archive for previous postings on the topic of 'hypermedia', for example, you would send an electronic message to a Listserv, perhaps, PACS-L, which is archived at
Listserv@uhupvm1.bitnet. Leave the subject line blank and type the following in the body of the message.

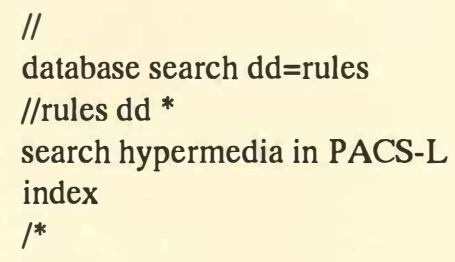

The Listserv will return a file with a numbered list of all messages that have appeared on the list with the keyword 'hypermedia' in them. To retrieve the messages a second electronic message, repeating much of the first message, must be sent to the list giving the numbers of the messages you would like to receive. The second message is typed as follows:

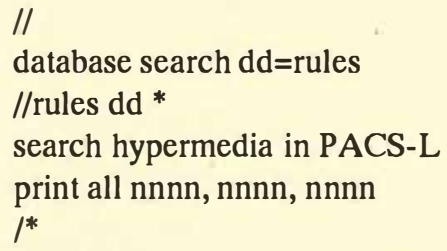

A more complete description of this process is available in Crossing the Internet Threshold. ${ }^{6}$ You can also have the Listserv send you a document with all search commands by sending the electronic message: INFO DATABASE to a Listserv site. As with a SUBSCRIBE command, leave the subject line blank.

\section{Usenet}

A discussion of lists would not be complete without mentioning Usenet. There are approximately three thousand discussion groups, referred to as 'newsgroups' handled by a volunteer network called Usenet. Usenet discussion groups often mirror, i.e. duplicate, discussion groups handled by Listservs on the Internet, or vice versa. The difference between newsgroups and Internet lists lies in the method of distribution. Internet postings are sent to individual subscribers while sites that offer Usenet receive a news feed of all Usenet groups, which are then accessed from a single central location. If you are following a discussion group on Usenet, you will sign on to a Usenet service and read the message from a central location rather than having it sent to your 'mailbox'. Unlike other electronic messages Usenet messages will not wait indefinitely for you to read them. They generally expire after three weeks. You cannot read newsgroup postings unless your site subscribes to Usenet. A good article on the advantages of Usenet over Internet has been written by Greg Notess in Online magazine. ${ }^{?}$

\section{ELECTRONIC JOURNALS AND NEWSLETTERS}

Electronic journals come in varying styles and formats. Some are refereed and claim scholarly status, others are more of the newsletter type or are extensions of discussion lists. Although most electronic journal articles are in ASCII format, accompany- 
ing picture files are becoming more common. Many electronic journals are managed and archived by Listservs. Delivery format varies from journal to journal. You may be sent either the entire journal, abstracts of the articles, or an index to the table of contents. The tables of contents of more and more electronic journals are showing up at gopher sites turning gophers into electronic newsstands. If the format consists of an index or abstract, you will be required to FTP any article you may wish to read. For information on how to gopher and FTP refer to the sections on these subjects below.

Electronic journals in the field of education are varied, with subjects ranging from $\mathrm{K} 12$ teaching to higher education administration. The following titles are included to give you an idea of what is available. For an up to date list of electronic journals refer to the Directory of Library Oriented Lists and Journals or the Directory of Electronic Serials mentioned below in the section on Keeping In Touch With The Internet. For background information on accessing ejournals, the reader is referred to the article Accessing Electronic Journals. ${ }^{8}$

\section{ACADEME THIS WEEK - \\ The Chronicle of Higher Education}

ACADEME THIS WEEK includes an overview of the news in the Chronicle of Higher Education, a calendar of the weeks events, deadlines for scholarships, and position openings. It appears every Tuesday on most gopher servers. It can be found in the menu under North America/ United States/Electronic Journals and Newsletters. If your site has a gopher client you can access it by gopher directly as follows: GOPHER Chronicle.merit.edu.

\section{DEOSNEWS - Distance Education Symposium Online}

DEOSNEWS is a bi-weekly, international, electronic journal of distance education. Articles in DEOSNEWS vary in tone from scholarly to conference reports and bibliographies. DEOSNEWS is managed by a Listserv. The process forsubscribing is similar to joining a list. To subscribe to DEOSNEWS send an electronic mail message to: Listserv@psuvm.bitnet. Do not write anything in the subject line. The complete text of the message should read:

\section{SUBSCRIBE Deosnews Yourfirstname Yourlastname}

When your request is received by the Listserv, you will be asked to confirm. Instructions on how to do so will be sent with the acknowledgment.

\section{EDUPAGE}

EDUPAGE, a service of EDUCOM, is a newsletter with brief news summaries of happenings in the world of information technology. It is international in scope and covers industry, govermment and educational topics. Summaries are from publications as diverse as The New York Times, Wall Street Journal, BNA Daily Report for Executives, Consumer Reports, Toronto Globe and Mail, and the Chronicle of Higher Education. It also includes notices of conferences. EDUPAGE appears twice a week. To subscribe to EDUPAGE send and electronic mail message to: Listproc@educom.edu.Leave the subject line blank. The complete text of your message should read:

\section{SUBSCRIBE edupage Yourfirstname Yourlastname}

\section{IPCT - Interpersonal Computing and Technology: an Elec- tronic Journal for the 21st Century}

IPCT is a peer reviewed journal. Topics of articles in IPCT that are of interest to educators and librarians include: use of electronic networks in the classroom and professional communication. The journal is oriented toward social science or humanities aspects of electronic communication. It is distributed by a Listserv. If you are subscribed, you will be sent abstracts of the articles in each issue. Each abstract will have a filename. If an article appears interesting, it can be retrieved by sending the electronic mail message: GET filename. To subscribe to IPCT send an electronic mail message to: Listserv@guvm. georgetown.edu. Do not type anything in the subject line. The complete text of the message should read:

\section{SUBSCRIBE Ipct-j Yourfirstname Yourlastname}

The IPCT journal is also available by gopher from Georgetown University. If your site has a gopher client you can access it by gopher directly as follows: GOPHER Guvm.ccf. georgetown.edu.

\section{JTE - Journal of Technology Education}

The Journal of Technology Education is handled by the JTELdiscussion list. The journal includes both text and graphics. The graphic files are in PostScript format. To subscribe to JTE send and electronic mail message to: Listserv@vtvm1.bitnet. Leave the subject line blank. The complete text of the message should read:

SUBSCRIBE Jte-1 Yourfirstname Yourlastname.

\section{LIBRES}

LIBRES is a quarterly journal, which publishes both research and application-oriented articles dealing with library and information science. The journal began publishing refereed articles in October 1993. To subscribe to LIBRES send an electronic mail message to: 
Listserv@kentvm.bitnet. Leave the subject line blank. The message should read:

\section{SUBSCRIBE Libres Yourfirstname Yourlastname}

\section{New Horizons in Adult Education}

New Horizons in Adult Education is archived by the AEDNET discussion list. To get a copy of the index of New Horizons send an electronic mail message to: Listserv@ alpha.acast.nova.edu. Leave the subject line blank. Type the following request in the body of the message:

\section{INDEX Horizons}

You will receive a mail message from the Listserv containing a list of available New Horizons journals. The file name for the different volumes are made up of the volume and number of each issue, i.e. file vol5n1 is volume 5 number 1 . To receive a particular volume send a request as follows:

\section{GET Horizons vol5n1}

The contents will be sent to you by electronic mail. If you like you can send several requests in one message. Put each request on a separate line.

\section{Online Chronicle of Distance Education and Communication}

The Chronicle of Distance Education is not a journal but rather publishes abstract of articles published elsewhere. It appears twice a year and includes course, program and conference announcements, information on new ejournals and discussions on distance education. Its scope is international. To subscribe to the Chronicle send an electronic mail message to: Listserv@ uwavm.bitnet. Leave the subject line blank. Type the following request in the body of the message:

\section{SUBSCRIBE Disted Yourfirstname Yourlastname}

\section{Public Access Computer Systems Review} (PACS-Review)

PACS-Review is a refereed journal concerned with end-user computersystems in libraries. It is published by the University of Houston Libraries. Coverage includes end-user computer systems, campus wide information systems, CD-ROMLANS, document delivery systems, expert systems, multimedia and more. To subscribe to PACS Review, send a message to: Listserv@ uhupvm1.bitnet. Leave the subject line blank. Type the following request in the body of the message:

\section{SUBSCRIBE Pacs-p Yourfirstname Yourlastname}

\section{DATABASES ON THE INTERNET}

Many library OPACS and gopher sites have databases or indexes and abstracts listed on their menus. In most cases, due to licensing agreements, or overload on the system, they are limited to persons affiliated with the institution supporting the OPAC or gopher. There are, however, a few that are open to the general public. Those that are useful for education are mentioned below.

\section{Canadian Education Index}

The Canadian Education Index, which is available at the University of Saskatchewan, includes French and English citations for monographs, theses, reports and journal articles. To access the database telnet to the University of Saskatchewan:

Telnet sklib.usask.ca

Login: SONIA (one of the few logins that uses upper case) CARL Uncover Article Access and Delivery

The CARL UnCover database produced by the Colorado Alliance of Research Libraries is a journal article database that offers table of contents access, and document delivery, for approximately 12,000 journal titles covering subjects in social sciences, sciences, education, humanities and medicine. Uncover can be consulted via the Internet free of charge. The searcher pays only for those articles that are ordered. Delivery charges are indicated clearly before the order is placed and vary depending on the amount of the copyright clearance fee. Gateway access is available for a fee. To access UnCover telnet to: database.carl.org and follow the on screen instructions for new users. An added bonus with Uncover is that it also provides a gateway to the British Library Document Delivery Service.

\section{Distance Education Database}

This is the database of the International Centre for Distance Learning at the UK Open University. It contains information on theory, policy, access and development of distance education. It also lists courses, distance teaching institutions and journals on the subject of distance education. It is international in scope and can be accessed by telnet.

Telnet acsvax.open.ac.uk

At the welcome prompt type: icdl

At the Account prompt type: name of your country

At the password prompt type: AAA (this does not show up on the screen)

Follow the menu to search institutions, courses, or the literature database.

ERIC (RIE and CIJE) 
The ERIC database is available for searching from a number of sites. Two popular sites are at the following telnet addresses:

University of Saskatchewan:

1.Telnet sklib.usask.ca

Login: SONIA (one of the few logins that uses upper case)

Syracuse University:

2.Telnet acsnet.syr.edu

Login: suinfo

Different sites offering access to the ERIC database have various capabilities in terms of time span of the database or fields that can be searched. To find out which one best suits your purposes you should try the individual sites. You can obtain the addresses for other sites from the ERIC Public Access System. The ERIC gopher will mail you a list of these sites with telnet addresses and logon instructions. At the time of writing the list of Internet access points for ERIC was in the following menu.

1. Gopher (AskERIC Electronic Library)

3. Library of Education Resources/

1. Full Text Education Information/

1. AskERIC Helpsheets/

1. Browse helpsheets by Topic/

3. Eric_Internet Access.

\section{INTERNET TOOLS}

Telnet

\section{Connecting to a Telnet Site}

Telnet is an Internet protocol that enables a connection from your home computer to a remote computer site. Telnetting to another site requires the presence of Telnet software on your local system. The basic command used to telnet, and the one you will almost always use, is TELNET. To connect to another site type 'Telnet' accompanied by a Telnet address. When you are in Telnet mode type a question mark for help or to view the other available commands.

Once you are connected to the remote site you will receive a 'login' prompt. Telnet addresses are usually accompanied by a login password, which will vary depending on the purpose of the telnet session. It is always entered in lower case. Once you are logged in, you may investigate any of the options that are designated as available for that particular password. Generally the types of information available, are Online Catalogues, Campus Wide Information Systems (CWIS), Wide Area Information Systems (WAIS), Citation or Full Text Databases and Archie or Gopher servers.

Telnet instructions for accessing many of these services are included in the section below: Keeping In Touch With The
Internet. File transfer is not an option at a Telnet site, however, you can access some gopher sites from a telnet site and have files 'mailed' to you by the gopher. Difficulties may be experienced in telnetting to or from an IBM TN3270 site. Communicating with these sites requires a different protocol, which must be present on your local system just as the basic Telnet protocol is. There are, however, sufficient sites that are not TN3270 to keep you busy for quite some time. ${ }^{9}$

\section{GOPHER}

Gopher is software that organizes files at various Internet sites and makes them available through a system of hierarchical menus. Gopher software has search and retrieval capabilities and many gophers will also deliver requested information to you. To use the gopher mail function, you must first be reading a file. When you exit the file you will be presented with the mail option $<\mathrm{M}>$ on the menu appearing at the bottom of the screen. When you choose mail, you will be prompted for your Internet address. Depending on how busy the network is at the time, the file will arrive in two minutes to two hours.

\section{Connecting to a Gopher Site}

There are two ways to reach a gopher site. One, if you have a gopher client at your site you can gopher directly to another site using the GOPHER command followed by the address of a gopher site, for example, GOPHER gopher.cua.edu. (Yes, some gopher addresses begin with the word 'gopher'). Two, if you do not have a gopherclient, you can telnet to some gophersites and login as 'gopher'. You can then reach other gophers by selecting 'Other gopher sites/' from the menu. Gophers not only provide access to information at their site and to other gophers, but serve as gateways to other services such as Hytelnet and the World Wide Web (WWW). Most gophers have a menu option offering introductory information about the gopher. It is a good idea to read these introductory files until you are familiar with the site. Gopher menu options are identified by either a text abbreviation, a symbol, or an icon at the beginning or end of the menu line. Some of the more common menu options are identified as follows:

/ or $<$ dir $>$ indicates the menu item is a directory.

. or $\langle$ Text $\rangle$ indicates the menu item is a text file.

? or <Index-search> indicates a searchable file.

indicates the item is a binary file.

indicates telecommunication connection to a telnet site. indicates a CSO phone book.

A word of caution: During login, a typographical error in the word 'gopher' will cause the system to prompt you for a password. Even if you spot and correct the typographical error and it appears correct on the screen you will be required to re-enter the 'gopher' login. Bypass the password prompt with a carriage return and start the login process again. Please note also that with the exception of Macintosh files that have been converted to ascii 
format (.hqx), non-ascii files cannot be retrieved, displayed or mailed by gophers. If you receive an error message indicating that a file is not available, this is generally the cause.

\section{Bookmarks}

Gopher sites are constantly under development, changing re-arranging and adding new information. On a single gopher you will find files on almost any subject, from Gardening to White House Press Releases and Presidential Speeches. Advanced gopher users will want to investigate the 'Bookmark' feature that allows you to create your own menus of frequently used directories by marking them for inclusion in your personal directory. Bookmark capabilities vary from site to site. Check with your local technical support to see what is available.

\section{Education Related Gophers}

\section{ERIC Public Access System}

ERIC (Educational Resources Information Clearinghouse), supports a gopher at its Public Access Site, called the AskERIC Electronic Library. Persons who access this gopher will find a cornucopia of education related information. Layer upon layer of menus and submenus include: classroom guides; lesson plans; Listservs (discussion groups); ERIC digests; and education statistics. Roy Tennant's Internet Basics ${ }^{10}$ can be accessed through the AskERIC Helpsheet menu and by tunnelling through a few submenus you will arrive at the University of Syracuse ERIC bibliographic database. The ERIC gopher also has access to other gophers including: The Coalition of School Networking; the University of Pennsylvania Literacy Research Center; and the National Centre for Education Statistics.

To access the ERIC Electronic Library telnet to the Public Access System at ericir.syr.edu

Telnet ericir.syr.edu

login: gopher (lower case)

If your local system supports a gopher, you can also gopher directly to ERIC Electronic Library: GOPHER ericir.syr.edu

\section{AskERIC}

AskERIC, a question answering service for teachers, administrators and other persons involved in $\mathrm{K}-12$ education, is available as a menu option from the ERIC Public Access Site. "The hallmark of AskERIC is the presence of a human intermediary to negotiate and respond to all questions posted to the system."11 There are two ways of transmitting questions to AskERIC. One, questions can be sent as an electronic mail message to: askeric@ericir.syr.edu. Two, you can access the AskERIC service by telnetting or gophering to the ERIC Public Access System and selecting it from the menu as follows:

telnet ericir.syr.edu

login: gopher (lower case)

terminal type: vt100
At the moment of writing the AskERIC feature was at menu option (2): AskERIC a Question. If you choose this option, you will be prompted for your question and given instructions on how to terminate. The answering service will also provide help with Internet related questions.

\section{ERIC Assessment and Evaluation Gopher}

The ERIC Assessment and Evaluation Gopher is sponsored by the ERIC Clearing House on Assessment and Evaluation, the Catholic University of America Education Department and the Catholic University of America Computing Center. The scope of ERIC/AE includes methodology, research, application of tests, measurement or evaluation of projects and programs, and learning theory. Menu items include, among others, Buros Test Review Locator, the Princeton ETS (Educational Testing Service) database and much more. If you have access to a gopher client the Assessment and Evaluation gopher can be reached directly: GOPHER gopher.cua.edu

When you have connected to the gopher, choose 'Special Resources/' from the menu. If you do not haveaccess to a gopher, telnet to the ERIC Public Access System: telnetericir.syr.edu and select it from the menu of the Electronic Library.

\section{U.S. Department of Education/OERI Institutional Communications Network (INET) Gopher Server}

The OERI gopher provided under the auspices of the U. S. Department of Education's Institutional Communications Network is managed and operated by the Education Information Resources Division of the Office of Educational Research and Improvement (OERI/EIRD). It provides access to education research, statistics and information about the United States Department of Education. The gopher includes information produced by, among others, OERI programs such as the National Centerfor Education Statistics (NCES), Education Research and Development Centers and ERIC.

You cannot telnet to this gopher. You must gopher to it as follows: GOPHER gopher.ed.gov. If your Internet site does not have a gopher client you can access the OERI gopher through the AskERIC Public Access System or on many other gopher sites you will find it under: All the Gopher Servers in the World/ North America/ USA/ General/ U.S. Department of Education/

\section{IBM Kiosk for Education (IKE) User Forum}

This is a gopher server for the exchange of information among faculty, staff and students in higher education on the use of IBM hardware and software systems for instruction and research. Among the subjects covered are: libraries, business, computer science, and education. New users must register in order to participate in the forum. Registration is menu driven and relatively simple. To register telnet to: Isaac.engr.washington.edu. 
Follow the on-screen instructions. IKE is also available by choosing IBM ACIS Higher Education Information Server - IKE from many other gopher menus.

\section{The Library of Congress}

The Library of Congress gopher, LC MARVEL, offers access to Library of Congress information, plus connection to other Internet gophers and services. Options from the main menu include: Research and Reference; Services to Libraries and Publishers; Copyright; and Global Electronic Library by Subject. Buried in a submenu is access to the Library of Congress Catalog and other useful resources such as the Directory of Scholarly Electronic Lists, ${ }^{12}$ and Library Oriented Lists and Serials. ${ }^{13}$ To access the Library of Congress gopher type the following:

\section{GOPHER marvel.loc.gov}

If you do not have a gopher client you can also telnet to MARVEL:

TELNET marvel.loc.gov

Or, if you just want to search the Library of Congress Catalog, it is available on its own via telnet:

TELNET locis.loc.gov

Login: locis

Ontario Institute for Studies in Education (OISE)

This information site provides access to a number of education resources including the Canadian Education Index, the Ontario Resources Information System database, ONTERIS, plus a gateway to othergophersites and the University of Toronto Library system. and other gophers. To access OISE:

Telnet eloise.oise.on.ca

login: eloise

If you have gopher capability, you can gopher directly to OISE at PORPOISE.OISE.ON.CA.

\section{Searching for Gopher Files: Veronica}

VERONICA stands for Very Easy Rodent Oriented Software. In simple terms, it is search software for retrieving files found in gopher menus. Veronica shows up as an option on most gophers. You can use Veronica for simple searches without knowing much more about it than that. For example, if you wanted to find out about Fidonet you would select Veronica from a gopher menu and enter the word 'fidonet' at the search prompt. The system will return approximately 50 references to items on Fidonet. The gopher software will mail any one of the items to you. If you want to do more complex searches, a help sheet on 'How to Compose Veronica Queries' is available after you choose Veronica from the gopher menu. Veronica can handle complex searches and has features that include restricting a search to certain gopher item types, Boolean operators and nesting. Given the large number of files that are searched in a Veronica search, learning to refine your search is a good idea.

\section{Searching Remote Computer Sites: Archie}

Archie is indexing software with a query module that makes it possible to locate files stored at remote computer sites. Remote means anywhere that you are not. Literally, this can be anywhere in the world. You would use Archie to locate a file or a program that you knew was available via FTP. In order to use Archie, you must first TELNET to a site that has an Archie server. Some popular addresses for Archie sites are: ds.internic.net; archie.rutgers.edu; archie.uqa.ca; archie.sura.net. These addresses, and more, can be found by connecting to Hytelnet at the University of Saskatchewan. Look for them under 'Other Resources'. Information on how to access Hytelnet will be found below under Keeping In Touch With The Internet. Once you are connected to the site you want to search, you will receive a login prompt. The login is: 'archie'. Do not include the quotes. Always use lowercase.

Telnet archie.sura.net

Login: archie

Archie commands can be obtained from an Archie site by typing in the HELP command. To get started, all you need to know is the basic search command which is PROG. For example, you have heard of a program called Mosaic. A recent article in the New York Times says it is free for Internet users who are willing to download it. ${ }^{14}$ You are intrigued by the wonders of Mosaic but no matter how many times you read the article, there is no indication of how or where to get the sof tware. This is a case for Archie. You can use Archie to find the address of a computer site that is storing Mosaic.

After you have logged into an Archie site the command: PROG Mosaic will retrieve a list of addresses that are storing the Mosaic program. At first sight, the list may appear cryptic. However, the information is easily decipherable. The first line of an entry lists the 'host', which is the site where the file is stored. The second line gives the date of last update. The 'location' is the directory where the file is stored. Directory names usually contain significant information. For example, 'pub' stands for public. These are the files that are open to the public. If one of the directories in the path is 'Mac' this means that the software in that directory is for use with a Macintosh computer and so on. Information on the 'file' line gives the name of the file to be retrieved, its size and date. If you are accustomed to reading DOS directories you will note that the information in a Unix directory is reversed and that file names appear at the end of a line and can spill over to the next line. Also, they do not follow the usual eight character filename rule with a three character file extension. The following is extracted from an archie search for Mosaic: 
Host ftp.luth.se

Last updated 16:15 4 Feb 1994

Location: /pub/infosystems/www/ncsa/Mac/1.0

FILE -r-r-r-663696 bytes NCSAMosaicMac.10.sit.hqx

Host ftp.ncsa.uiuc.edu

Last updated 15:20 6 Feb 1994

Location: /PC/Mosaic

FILE -rw-r-r- 250267 wmos20a1.zip

The file names in these examples are: NCSAMosaicmac .10.sit.hqx and wmos20a1.zip. In order to retrieve a copy of Mosaic, you must exit the telnet connection and use the FTP command, which is described below.

File Transfer Protocol (FTP)

File Transfer Protocol (FTP), also known as Anonymous FTP, is a set of rules that governs the exchange of inf ormation on the Internet. It is used to transfer files of all types from a remote computersite to your home computer. The 'anonymous' refers to the fact that access to the files in question does not require a user identification. The files you transfer will be located in a section of a mainframe that allows public access. There are a few basic things to remember when you FTP. One, transfer your files during non-peak times if possible. They will transfer faster and you will not be tying up the network. Two, if you FTP a shareware program you must register and pay the fee if it is required to do so. Three, there are many different file types available for transfer and most FTP sites store a wide variety of them. All non-ascii files must be transferred with the binary command as indicated below. Before you FTP a file you can tell what kind of a file it is by the file extension. Common file types are .doc, .txt, .ascii, .MS-DOS, .hqx, and .Zip. A recent article in The Computing Teacher gives a good explanation of the various file types and how to transfer them. ${ }^{15}$

ToFTP a file, log on to your home computer in the usual way. At the initial prompt type in the FTP command followed by the address of the site that is storing the file. For example, to FTP to one of the sites that is storing Mosaic: FTP ftp.ncsa.uiuc.edu.

It is not unusual foran FTP address to contain the letters ' $\mathrm{ftp}$ ' within the address.

When you are connected to the host computer, you will receive a message telling you that the connection has been made. The prompt will indicate the name of the computer you are connected to. Complete the connection as follows:

At the site prompt, type: login

At the name prompt type: anonymous

At the password prompt type your email address: soandso@XXXXX.yyy.ca

A welcome message will appear and you will find yourself in the root directory. To navigate between directories use the $C D$ (change directory) command. For example : CD /comp.archives/ alt.hypertext. Notice that the slashes are forward slashes rather than reversed as they are in a DOS directory. To transfer the file, type:

FTP $>$ Get /path/filename

A WORD of CAUTION: Many FTP sites are case sensitive. You MUST use upper and lower case EXACTLY as it appears in the address. If a file name is NCSAMosaicMac, that is the way it must be entered. Many unsuccessful attempts to transfer a file are simply the result of typing a single letter in upper instead of lower case and vice versa.

Binary files, that is to say all non-ASCII files must be transferred in binary format. To do this type the word 'binary' at the FTP prompt, before you use the GET command

\section{FTP>binary \\ FTP $>$ Get /path/filename}

You will then be prompted to give a local file name. This is the name the file will have on your home computer.

\section{KEEPING IN TOUCH WITH THE INTERNET}

\section{Finding Electronic Journals and Lists}

Directories of electronic journals and discussion groups can be obtained by electronic mail, or file transfer and can also be consulted at many gopher sites. Two of the more popular directories are: The Directory of Scholarly Electronic Conferences, ${ }^{16}$ and the Directory of Electronic Serials. ${ }^{17}$ A selected list of journals and discussion lists of interest to libraries has been put together by Charles Bailey. ${ }^{18}$ Yet another list is being archived by the Committee for Institutional Cooperation. In order to retrieve any of these list follow the individual instructions below.

\section{The Directory of Scholarly Electronic Conferences}

This is a directory to electronic publications including discussion lists, electronic journals, newsletters, and Usenet groups. The size of this list requires that it be broken up into several manageable sized files. It is available in both ascii and hypercard formats. The files can be retrieved by electronic mail or FTP.

To retrieve the directory by electronic mail send a message to: Listserv@kentvm.kent.edu. Leave the subject line blank. The first file you should retrieve is the README file, which has explanatory notes for retrieving the remainder of the directory. To do this, type the following in the body of the message: GET Acadlist readme.

To retrieve the directory by file transfer, FTP to: Ksuvxa.kent.edu. Login: anonymous. Use your email address as password. To retrieve the README file, type: GET Acadlist readme. 


\section{Directory of Electronic Journals}

This directory of electronic journals, compiled by Michael Strangelove at the University of Ottawa, is also very large and has been broken into two sections. To retrieve the directory, send an electronic mail message to: Listserv@acadvm1.uottawa.ca.The body of the message should read:

\section{GET EJOURNL1 DIRECTRY F=MAIL GET EJOURNL2 DIRECT'RY F=MAIL}

Note that the two files have vowels missing. Type the file names as they appear here.

\section{Library Oriented Lists and Electronic Serials}

This list can be obtained on many gophers. It is generally found under a heading for Library/ Electronic Journals and Newsletters/.

\section{CICNet}

CICNet, founded by the Committee on Institutional Cooperation ( $\mathrm{CIC})$, a group working at providing access to Internet resources, connects a large number of academic, research, nonprof it and commercial organizations in the midwestern United States. The resource that is most popular on CICNet is the archive of electronic journals. The archive is a menu choice on many gophers. If you have a gopher client you can gopher directly to: gopher.cic.net. The contents of this gopher are also available via anonymous FTP: ftp.cic.net. Directory is :/pub/nircomm/gopher

\section{FURTHER RESOURCES}

\section{CLEARINGHOUSE FOR SUBJECI'-ORIENTED INTERNET GUIDES}

The University of Michigan Library and the School of Information and Library studies sponsor a clearinghouse for subject oriented internet guides. Subjects include: buddhism, law, psychology, education and library studies. There are presently over fifty guides at the site. The guides are available via anonymous FTP or through several gophers. To retrieve a file, FTP to: una.hh.lib.umich.edu. The directory is: inetdirsstacks. File names in the directory describe the contents of each guide. Pick one that interests you and FTP it as described in the File Transfer section above. If you have a gopher client, you can gopher directly to: gopher.lib.umich.edu.

\section{CURRENT CITES}

Current Cites, published by the library at the University of California, Berkeley, is a monthly annotated bibliography cover- ing internet related topics. Journals in library and information technology are scanned for selected articles. Topics include: optical disk technologies, computer networks and networking, information transfer, artificial intelligence, electronic publishing, and hypermedia. To subscribe send a request to: cites@library.berkeley.edu. Alternatively, you can FTP to the archive site at Berkeley. The FTP address is ftp.lib.berkeley.edu. The Current Cite files are in the directory/pub/Current.Cites. A searchable archive is also available from the BRS system at the Coalition for Networked Information (CNI). To reach the CNI site, telnet to: a.cni.org. Login as: brsuser.

\section{HELP-NET}

HELP-NET is a list for network users who want to ask questions about the Internet. The questions, which are posted to all list members, cover a broad range of topics from 'how to show picture files' to 'how to receive Netnews.' Sometimes it may seem that there are more questions than answers, but the list will at least let you know that you are not alone. To subscribe to HELP-NET send an electronic mail message to: Listserv@templevm.bitnet. Leave the subject line blank. In the body of the message type the following:

SUBSCRIBE Help-net Yourfirstname Yourlastname

\section{HYTELNET}

HYTELNET is a hypertext based directory of available Internet resources kept up to date by Peter Scott at the University of Saskatchewan. Hytelnet includes addresses and relevant information for accessing online library catalogs throughout the world. In the past year it has added addresses for gopher sites, WWW sites, Freenets and more. Hytelnet is as valuable to the Internetas a phone directory is to the telephone. (It will not locate individuals, however). It is a menu choice on many gophers, and can also be accessed directly by telnetting to the University of Saskatchewan. Instructions for using Hytelnet are presented to you on the introductory menu. One nice feature of Hytelnet is its efficient search capability.

\section{TELNET ACCESS.USASK.CA}

Login: hytelnet (lower case)

Follow the directions on the screen

An electronic version of Hytelnet is also available for mounting on local systems.

\section{NET-HAPPENINGS}

NET-HAPPENINGS is sponsored by InterNIC Information Services. The list monitors several Internet sources and forwards postings to members of NET-HAPPENINGS. Forwarded messages include conference announcements, calls for papers, new 
publications, new lists, network resources, and newsletters of interest to the Internet community. There is no discussion on NET-HAPPENINGS, it is an announcements only list. To subscribe send an electronic mail message to: Listserv@is.Internic.Net. Leave the subject line blank. Type the following in the body of the message:

\section{SUBSCRIBE Net-happenings Yourfirstname Yourlastname}

A searchable archive of NET-HAPPENINGS is also available using the BRS system at the Coalition for Networked Information (CNI). To reach the CNI site, telnet to: a.cni.org.

\section{NETTRAIN}

NETTRAIN is a list for Internet and Bitnet users and trainers. Discussion centers on methods and procedures for Internet training as well as conference announcements and other news events. To subscribe to NETTRAIN send an electronic mail message to: Listserv@ubvm.Bitnet.Leave the subject line blank. In the body of the message type the following:

\section{SUBSCRIBE Nettrain Yourfirstname Yourlastname}

You will be asked to confirm your subscription. This is not an unusual request for high-volume lists.

\section{SPECIAL INTERNET CONNECTIONS}

This is a compilation of addresses for Internet services updated regularly by Scott Yanoff. The list includes telnet addresses for gophers and other interesting sites. It is organized by subject from aviation through education to space/astronomy. The list can be accessed by FTP:

ftp csd4.csd.uwm.edu.

cd /pub

get inet.services.txt

or by gopher:gopher csd4.csd.uwm.edu

\section{Virtual Reference Desk}

The virtual reference desk is a collection of 'bookmarks' to reference sources, which have been compiled by the University of California, Irvine and adopted by many gophers. This gopher item leads to menu items as far ranging as email addresses for the White House, Internet assistance, English language dictionaries and the Directory of Electronic Journals and Newsletters. One point of access to the virtual reference desk is through the University of Illinois gopher. Telnet to: ux1.cso.uiuc.edu, login: gopher. The University of Illinois gopher also has a list of gopher sites recommended for exploration.

\section{FAQ}

Frequently asked questions, also known as FAQs are available for Archie, Veronica and the Internet itself on many gophers. They answer all the right questions and are an excellentsource for basic information on these services. FAQs are located on most gopherservers. Pick your favorite gopher and go browsing. Once you have found the FAQ you need, have it mailed to you.

\section{Coalition for Networked Information (CNI)}

CNI is a joint project of EDUCOM, CAUSE and the Association of Research Libraries. CNI's mission is to promote the creation of and access to information resources in networked environments. Menu items include: copyright, coalition projects, network lists, and electronic journals. Telnet to a.cni.org. Login: brsuser

\section{INFOSOURCE: InterNIC Information Services}

This Internic service is a collection of information designed to help new and experienced users locate sources on the Internet. The Infosource will either provide the actual document or give details on how to access other information archives. To find out what is available consult the InfoSource Table of Contents. Infosource can be accessed through Telnet, FTP, and Gopher.

\section{FTP Access}

To retrieve documents from the InfoSource using anonymous FTP:

ftp is.internic.net

login: anonymous

password: your e-rnail address

cd infosource

get INDEX

The INDEX file, which will be mailed to you, contains a list of thefilenames and the directories of items archived at Inf osource. Files can be retrieved using FTP protocol.

To retrieve documents using a gopher client, gopher to: is.internic.net

If you do not have a Gopher client, telnet to: is.internic.net, login as: gopher (lower case).

Once in gopher space you can move up and down the menu system to see what is available.

\section{The Future of the Internet}

There are days when nothing seems right with the Internet. Connections are refused, searches take forever or longer, every item on a gopher is a binary file that cannot be retrieved, and the remote site ref uses to recognize you because you have misspelled 'anonymous'. The present, to say nothing of the future looks bleak. But there are days when an elusive piece of information 
comes your way without asking, sometimes even before you knew you were looking. All of which make it an understatement to say the Internet has a life of its own. Its capacity to blend with informational and educational needs is enormous and getting better all the time. New software, for instance, now makes it possible to enter into multimedia connections, and access to OPACS and free text sources present new opportunities for information professionals.

What has been presented here is a minute part of the Internet and networking. There are many aspects that have been impossible to comment on such as specialised educational networks, the proliferation of BBS in the K12 environment, and the emergence of Freenets. I hope that by using some of the resources mentioned above, readers will find out about and take an active part in their development.

\section{REFERENCES}

${ }^{1}$ Giguère, Marlene. (1992). "An introduction to services available on the Intemet." Education Libraries. 16, (2), 5-9.

"Silva, Marcos and Cartwright, Glenn F. (1993). "The Internet as a medium for education and research." Education Libraries. 17, (2), 7-12.

${ }^{3}$ Giguère, Marlenc. (1993). "The Internet: a selective annotated bibliography of print material." Education Libraries. 17, (2), 13-23.

${ }^{4} \mathrm{Krol}, \mathrm{Ed}$. (1992). The whole Internet: User's guide and catalog. Sebastopol, CA. O’Reilly \& Associates. p. 93-95.

${ }^{5}$ For a discussion on the difference between Internet and Bitnet addresses, the reader is invited to read: Arms, Caroline $\mathrm{R}$. (1990). Using the national networks: Bitnet and the Internet. Online 14, September, 24-29.

'Tennant, Roy, Ober, John and Lipow, Anne. (1993). Crossing the Internet threshold: an instructional handbook. Berkeley, CA: Library Solutions Press.

${ }^{7}$ Notess, Greg. (1993). “Usenet: Taming the Email flood”. Online. July, p. 86-88.

${ }^{8}$ Brandt, Scott D. (1992). Accessing electronic journals. Academic and Library Computing, 9, (10), November/December, p.17-20.

${ }^{9}$ There is a good discussion of TN3270 sites in: Krol, Ed. (1992) The Whole Internet: user's catalog and guide. Sebastopol, CA.: O'Reilly and Associates.

${ }^{10}$ Tennant, Roy. (1992). Internet basics. ERIC Clearinghouse on Information Resources. (ERIC Digest ED348054). [Computer file, available from AskERIC Virtual Library. Telnet or gopher to: ericir.syr.edu. Internet]

${ }^{11}$ Preston, Nancy. (1993) News from ERIC. EducationLibraries. 17, (2), 24-25.

${ }^{12}$ Kovacs, Diane, et al. (1993). Directory of scholarly electronic conferences. Listserv@kentvm1.kent.edu.

${ }^{13}$ Bailey, Charles W. (1993). Library oriented lists andelectronic serials. [Computer file, available from Library of Congress gopher. Telnet or Gopher to: marvel.loc.gov. Internet]
${ }^{14}$ Markoff, John. A Free and simple computer link.TheNew York Times, December 8, 1993. p. D1, 5

${ }^{15}$ Harris, Julie. (1993). Electronic packaging: File types for file transfer. The Computing Teacher. October, 33-35.

${ }^{16}$ Also available in print. Okerson, Ann (Ed.) (1993). The directory of electronic journals, newsletters and academic discussion lists. (3rd ed). Compiled by Michael Strangelove and Diane Kovacs. Washington: Association of Research Libraries, 1993.

${ }^{17}$ ibid.

${ }^{18}$ Bailey, Charles W. op cit.

Jacqueline Dealy is Education Librarian at the Webster Library, Concordia University, Montreal, Quebec, Canada. 